\title{
Genetics of pheochromocytoma and paraganglioma in Spanish pediatric patients
}

\section{Dear Editor}

Pheochromocytomas (PCCs) and paragangliomas (PGLs) are rare neuroendocrine tumors that arise from the adrenal medulla or from the extra-adrenal sympathetic and parasympathetic paraganglia respectively. Now we know that more than $30 \%$ of patients develop extra-adrenal tumors (Cascon et al. 2009b, Mannelli et al. 2009), the percentage of malignant cases depends on tumor location and/or genetic background (from $\sim 3 \%$ in RET- or VHL-related cases to 31\% described for $S D H B$ mutation carriers; Welander et al. 2011), and the probability of carrying a germline mutation in one of the PCC/PGL susceptibility genes is approaching 50\%. Regarding the latter, up to four genes (SDHAF2, SDHA, TMEM127, and $M A X)$ have recently been incorporated into the 'catalog' of PCC/PGL susceptibility genes (Hao et al. 2009, Burnichon et al. 2010, Qin et al. 2010, Comino-Mendez et al. 2011). Before the discovery of these genes, $30-40 \%$ of PCC/PGL cases were thought to be hereditary with autosomal inheritance caused by germline mutations affecting one of six major susceptibility genes: $R E T, V H L, S D H B, S D H C$, SDHD, and NF1 (Cascon et al. 2009b, Mannelli et al. 2009). Recent international collaborations, focused on establishing the involvement of the novel identified genes, suggested that overall they could explain an additional $6 \%$ of the negative-tested patients (Bayley et al. 2010, Yao et al. 2010, Burnichon et al. 2012). In addition to this high and heterogeneous genetic predisposition, there is a unknown percentage of familial cases (i.e. with familial antecedents of PCC/PGL and/or with other clinical characteristics suggesting a hereditary disease) that do not harbor mutations in any of the susceptibility genes mentioned earlier.

Although PCCs/PGLs are infrequently diagnosed during childhood, it is possible to find pediatric patients (diagnosed under the age of 18 years) either carrying germline alterations in the major susceptibility genes or without known mutations (Welander et al. 2011). The identification of a genetic predisposition in children has obvious implications regarding follow-up and treatment. In the case of PCC/PGL patients with germline mutations in $S D H B$, early genetic characterization is even more crucial considering their malignancy-associated risk. Given that four of the ten major PCC/PGL susceptibility genes were identified very recently, there are still not enough genotype-phenotype association studies to properly guide pediatric genetic diagnosis. In the present study, we describe clinical and genetic findings of 36 pediatric patients and compare them with data from 411 genetically characterized non-pediatric cases. The study includes the analysis of the nine major PCC/PGL susceptibility genes.

Consecutively registered patients included in this study were clinically diagnosed with PCC/PGL in public Spanish hospitals and referred to us for the genetic testing in the major PCC susceptibility genes: VHL, RET, SDHA, SDHB, SDHC, SDHD, SDHAF2, TMEM127, and MAX. No patients presented with the clinical features of neurofibromatosis type 1. DNA was obtained by standard procedures from blood samples from 447 apparently non-related index cases collected between 1995 and 2012 , with 36 patients classified as pediatric cases. Written informed consent was obtained for each patient or a legal tutor in the case of children. Complete genetic characterization of the susceptibility genes included, except for the $R E T$ oncogene, point mutation analysis of all exons and intron-exon boundaries, and assessment of gross deletions either by means of multiplex ligation-dependent probe amplification or by multiplex PCR. In the case of RET, point mutations affecting exons 10, 11, 13, 14, 15, and 16 were analyzed. We used DNA from 1000 unrelated and unaffected individuals as a control population for the study of variants of unknown significance. Differences between pediatric and non-pediatric probands were assessed using a $\chi^{2}$ test or Fisher's exact test when appropriate. Statistical analyses were carried out using SPSS Software, version 17.0 (SPSS, Inc.). To check whether there was any association between the type of mutation and the age at onset, we subclassified $S D H$ mutations into

Published by Bioscientifica Ltd. 
two different groups according to the predicted effect of the variant: truncating mutations (frameshift, nonsense, splicing, and gross deletion) and non-truncating mutations (missense and in-frame insertions/deletions). We compared the frequency of mutations from each group in pediatric with non-pediatric cases.

Clinical and genetic characteristics of the two series of patients compared in this study are described in Table 1. In total, $69 \%$ of pediatric cases carried a germline mutation in one of the susceptibility genes investigated, compared with $36 \%$ of non-pediatric probands $(P<0.001)$. Thirty-one percent $(11 / 36)$ of pediatric probands presented a family history of PCC/PGL, with mutations identified in 91\% (10/11) of them. An additional 42\% $(15 / 36)$ of cases, without family history, harbored a germline mutation. The involvement of each susceptibility gene in the pediatric cases was $11 S D H B$ cases, 8 $V H L$ cases (four de novo alterations), 4 SDHD cases, 1 MAX case, and 1 RET case. VHL and RET mutations were significantly more and less frequently detected $(P=0.02$, $P=0.004)$ respectively in children compared with nonpediatric cases. Table 2 and the Supplementary Material, see section on supplementary data given at the end of this article provide a clinical description of the 36 pediatric cases included in the study. When we compared the frequency of truncating and non-truncating $S D H B$ mutations between pediatric and non-pediatric probands, we found an over-representation of truncating mutations in the pediatric group $(P=0.06)$. We did not find such differences in the distribution of the $S D H D$ mutations.

In the absence of a family history of a particular disease, young age at onset is an important clinical feature that suggests a hereditary predisposition. In the case of PCC/PGL, this association is even more important, as a high percentage of hereditary cases is found among apparently sporadic patients (Cascon et al. 2009a). In our series, $69 \%$ of pediatric probands harbored a germline mutation in one of the nine PCC genes assessed. The percentages of probands with and without germline mutations were inversely proportional in the pediatric compared with the non-pediatric cases (Table 1). Our results are in agreement with a recently published study that described a staggering number of children with metastatic PCC/PGL carrying a SDHB germline mutation (King et al. 2011). Among the series of pediatric cases without mutations, we found a significantly higher proportion with at least one well-known clinical finding suggestive of a hereditary condition, such as bilateral PCC and coexistence of PCC and PGL $(P=0.008)$. Although no significant difference was found between mean age of onset among mutation-positive and -negative pediatric probands, two of the three cases younger than 10 years at onset belonged to the mutation-negative group. Altogether, it seems plausible that the majority of these negative-tested children indeed harbor a germline mutation in an as yet unknown gene.

We found that almost $60 \%$ of VHL carriers harbored a de novo mutation, in agreement with the $56 \%$ reported in Chinese patients (Wu et al. 2012). However, as the currently accepted de novo VHL mutation rate is estimated at $20-21 \%$ (Evans et al. 2010), it is likely that the high rate found in our series is due to sample size. As expected, none of the informative $S D H$ mutation carriers without familial antecedents had de novo mutations, suggesting a low mutation rate affecting the $S D H$ genes. In addition, half of the cases with antecedents showed affected second-degree relatives, in agreement with a heredity pattern involving imprinting and low-penetrance phenomena affecting $S D H D$ and $S D H B$ respectively. Although the estimated average penetrance of $S D H B$ mutations at age 20 is $1 \%$ (Schiavi et al. 2010), it is not surprising to find pediatric cases among SDHB-mutated pedigrees. The mechanisms behind this clinical discrepancy have remained elusive until now, but it seems that the nature of the mutation may be important. All $11 S D H B$ variants found in the pediatric probands were truncating mutations, compared with $72 \%$ for the non-pediatric probands. This overrepresentation of truncating mutations was not found for $S D H D$ variants. Similar to the 'proteotype-phenotype' correlation found for unstable SDHD mutations and an earlier age at onset described by Ricketts (2010), we observed a non-significant over-representation of truncating $S D H B$ variants in pediatric patients. Although most of the $S D H B$ mutations found in our pediatric probands are founder mutations in Spain (Cascon et al. 2006, 2009b), which may explain the high rate of $S D H B$ mutations found in this study, bias was avoided by comparing the frequency between only Spanish pediatric and nonpediatric patients from the same series. Although our results and those of Ricketts et al. (2010) concern different genes, it seems that as reported for VHL mutations, the nature of the $S D H$ variants could determine important clinical features such as the age of onset. In the present study, the number of mutations tested is limited and therefore evaluation of a larger series of SDH patients is warranted to validate these results, which could potentially change PCC/PGL clinical management.

Regarding other susceptibility genes, it is not surprising that we did not find involvement of the genes TMEM127, SDHC, SDHAF2, or SDHA in pediatric PCC/PGL

Published by Bioscientifica Ltd. 


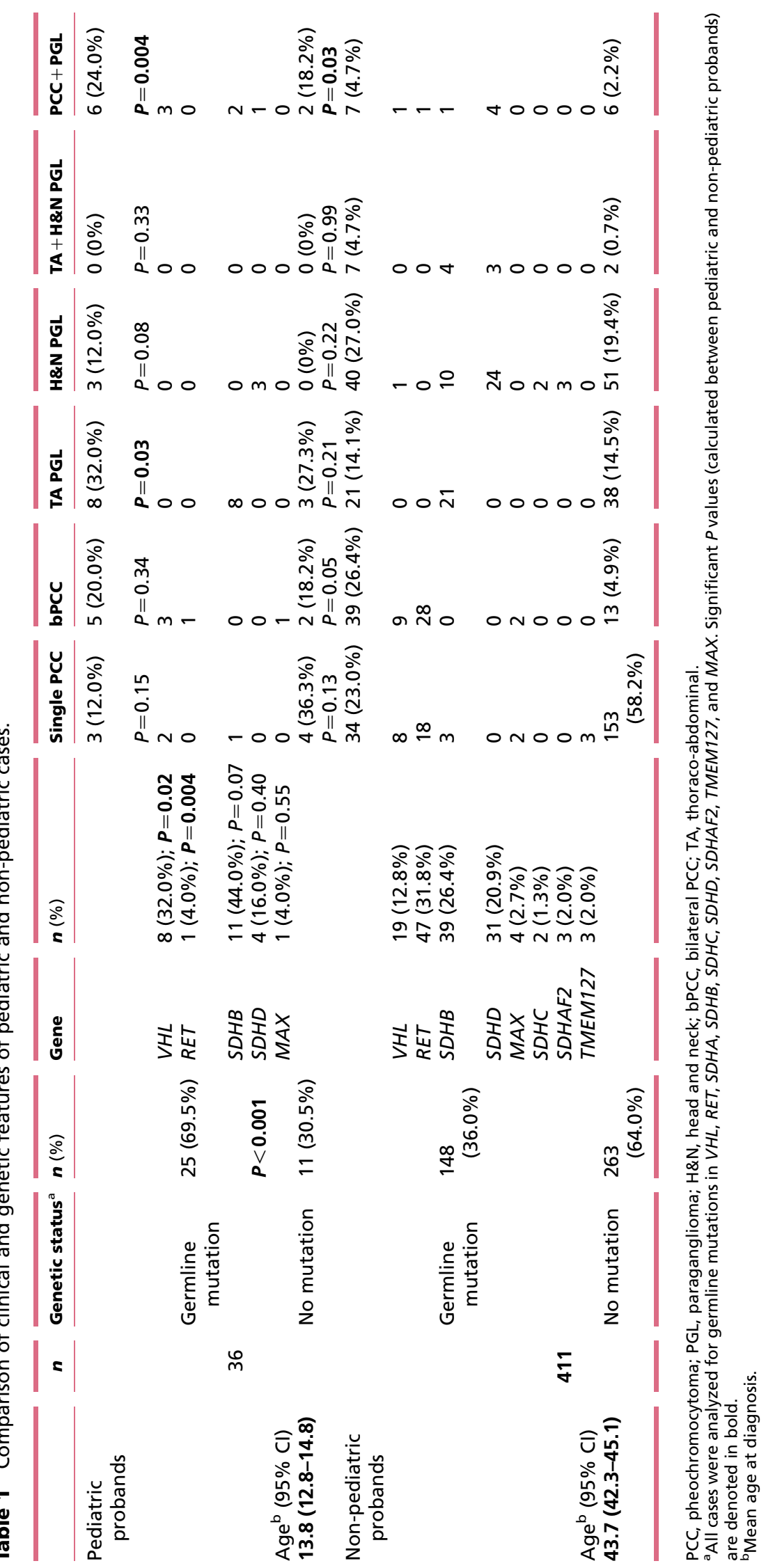




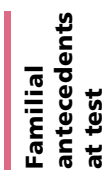

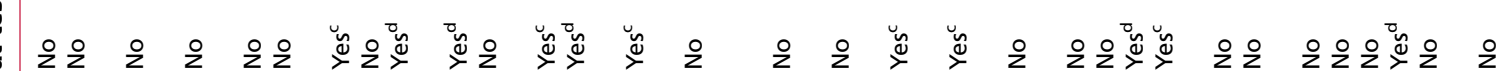
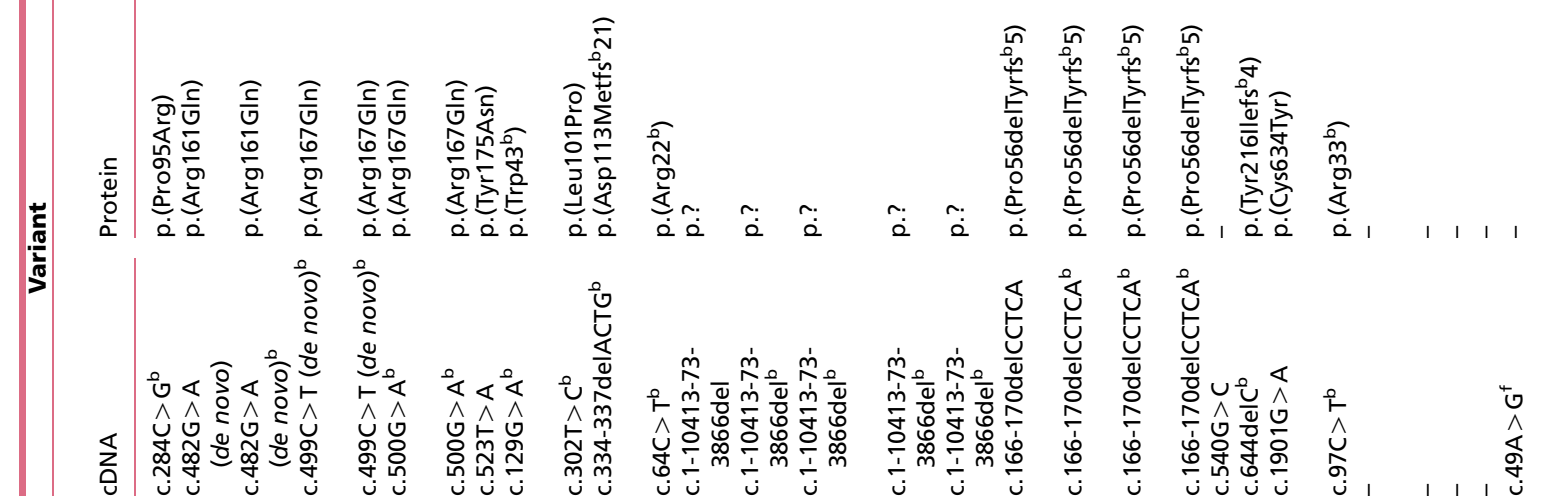

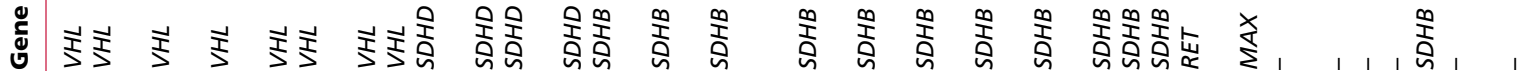

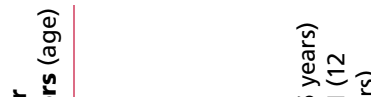

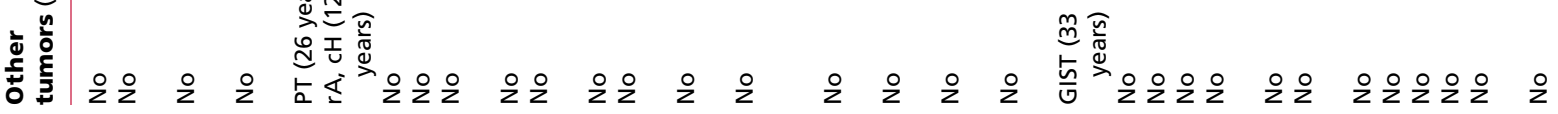
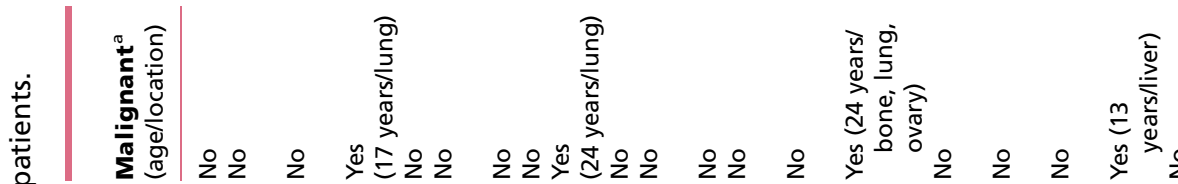

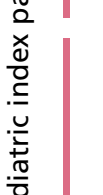

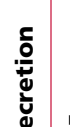

党

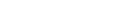

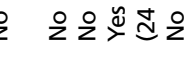

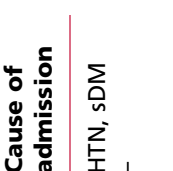

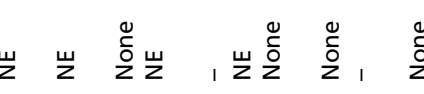

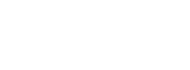

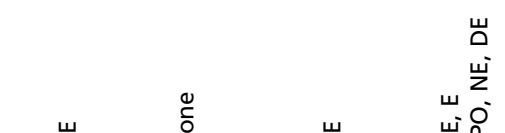

$\frac{0}{2} ﹎{2}^{\circ}$

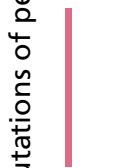

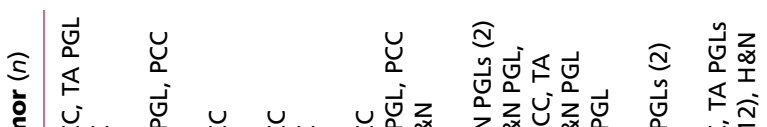

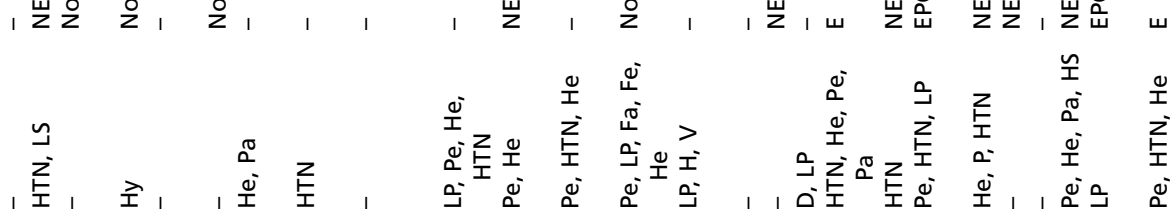

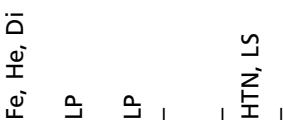




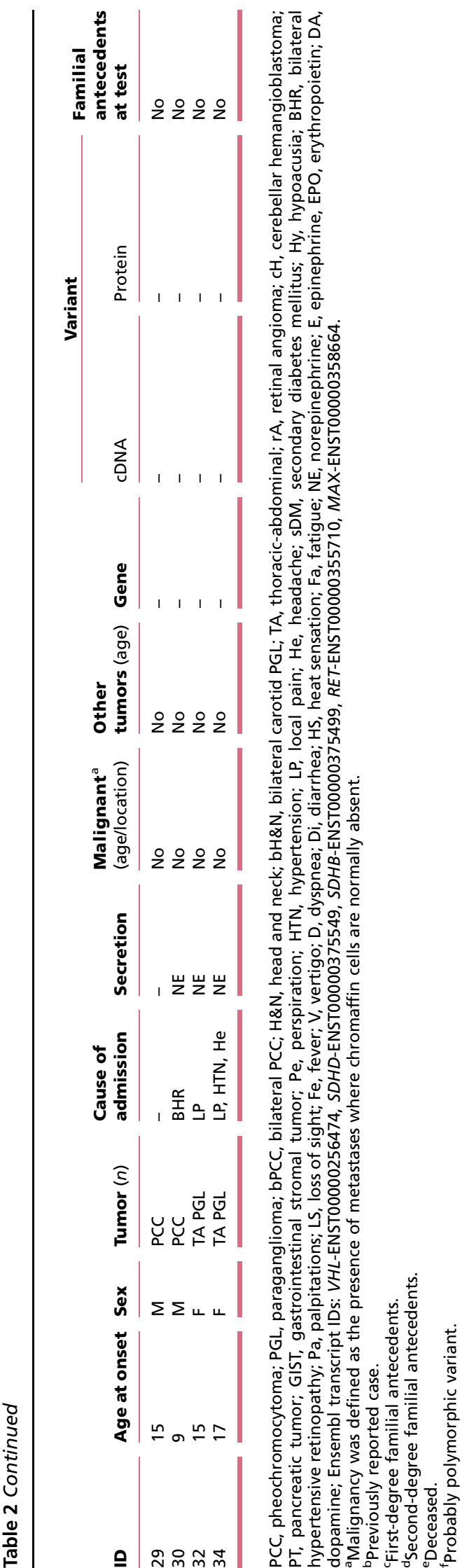

http://erc.endocrinology-journals.org DOI: 10.1530/ERC-12-0339
(C) 2013 Society for Endocrinology Printed in Great Britain development as patients with mutations in these genes have a higher mean age at presentation (Welander et al. 2011). Furthermore, these genes explain $\sim 2 \%$ of all PCC/PGL cases in our series, independently of the age of onset, so only by increasing the number of pediatric cases analyzed, we should be able to confirm the absence of association of these four genes with young-age PCC/PGL development. On the other hand, the occurrence of one $M A X$ case among pediatric probands is in agreement with its recently reported role as a PCC/PGL susceptibility gene (Burnichon et al. 2012). This finding becomes more relevant when considering that the prevalence of $M A X$ mutations $(1.1 \%$ in our whole series) is quite similar to that reported for the latest identified PCC/PGL susceptibility genes (Welander et al. 2011). Therefore, it seems justified to include $M A X$ in the genetic screening algorithms of pediatric cases with PCC. Further discussion of other genotype-phenotype associations is included in the Supplementary Material. Finally, the only proband with family history, and without any known germline mutation, had second-degree familial antecedents (i.e. an affected grandfather). Generationskipping also occurred in the two familial non-pediatric probands from our series without germline mutations (data not shown), which suggests the involvement of lowpenetrance variants or an imprinted gene.

In summary, genetic screening for mutations in the $S D H B, S D H D, V H L, R E T$, and $M A X$ genes is strongly recommended in pediatric PCC/PGL patients, starting with the metastasis-prone gene $S D H B$. Still unidentified PCC/PGL susceptibility genes will probably clarify the early tumor development of mutation-negative pediatric cases in the near future.

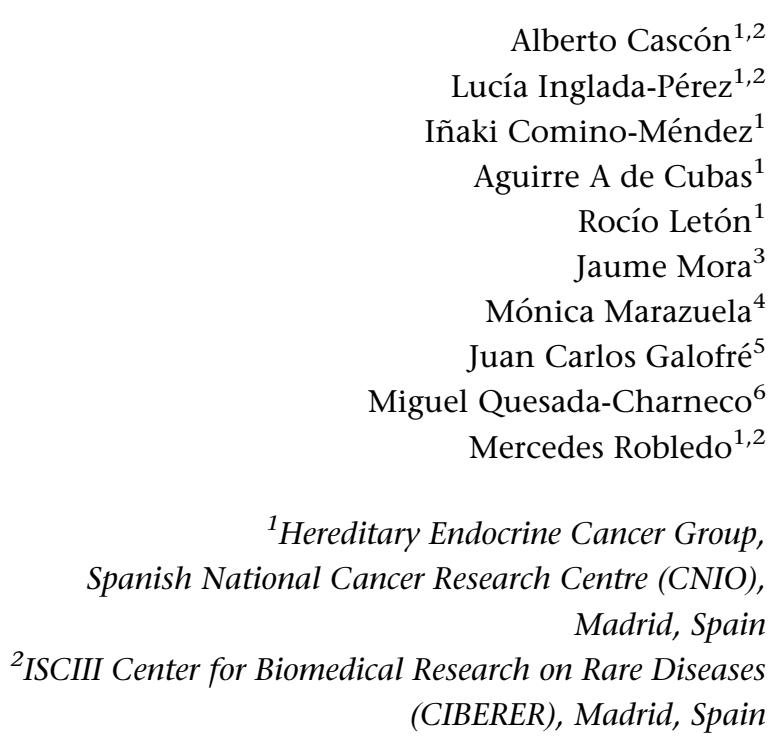

Published by Bioscientifica Ltd. 
${ }^{3}$ Department of Pediatric Oncology, Hospital Sant Joan de Déu, Barcelon, Spain

${ }^{4}$ Endocrinology Division, Hospital Universitario de la Princesa, Madrid, Spain

${ }^{5}$ Department of Endocrinology and Nutrition, Clínica Universidad de Navarra, University of Navarra, Pamplona, Spain

${ }^{6}$ Endocrinology Service, Hospital Clínico Universitario San Cecilio, Granada, Spain

(Correspondence should be addressed to M Robledo Hereditary Endocrine Cancer Group, Human Cancer Genetics Programme, Centro Nacional de Investigaciones Oncológicas (CNIO), Melchor Fernández Almagro 3, 28029 Madrid, Spain; Email: mrobledo@cnio.es)

\section{Supplementary data}

This is linked to the online version of the paper at http://dx.doi.org/10.1530/ ERC-12-0339.

\section{Declaration of interest}

The authors declare that there is no conflict of interest that could be perceived as prejudicing the impartiality of the research reported.

\section{Funding}

This work was supported in part by the Fondo de Investigaciones Sanitarias (projects PS09/00942 and PI11/01359 to A Cascón and M Robledo respectively), Fundación Mutua Madrileña (project AP2775/2008 to $M$ Robledo), and a grant from the Seventh Framework Programme (ENS @T-CANCER; HEALTH-F2-2010-259735). L Inglada-Pérez, A A de Cubas, and I Comino-Méndez are predoctoral fellows of the CIBERER, 'la Caixa'/CNIO international $\mathrm{PhD}$ programme, and the Fundacion Ferrer respectively.

\section{References}

Bayley JP, Kunst HP, Cascon A, Sampietro ML, Gaal J, Korpershoek E, Hinojar-Gutierrez A, Timmers HJ, Hoefsloot LH, Hermsen MA et al. 2010 SDHAF2 mutations in familial and sporadic paraganglioma and phaeochromocytoma. Lancet Oncology 11 366-372. (doi:10.1016/ S1470-2045(10)70007-3)

Burnichon N, Briere JJ, Libe R, Vescovo L, Riviere J, Tissier F, Jouanno E, Jeunemaitre X, Benit P, Tzagoloff A et al. 2010 SDHA is a tumor suppressor gene causing paraganglioma. Human Molecular Genetics 19 3011-3020. (doi:10.1093/hmg/ddq206)

Burnichon N, Cascon A, Schiavi F, Morales NP, Comino-Mendez I, Abermil N, Inglada-Perez L, de Cubas AA, Amar L, Barontini $\mathrm{M}$ et al. 2012 MAX mutations cause hereditary and sporadic pheochromocytoma and paraganglioma. Clinical Cancer Research 18 2828-2837. (doi:10.1158/1078-0432.CCR-12-0160)

Cascon A, Montero-Conde C, Ruiz-Llorente S, Mercadillo F, Leton R, Rodriguez-Antona C, Martinez-Delgado B, Delgado M, Diez A, Rovira A et al. 2006 Gross SDHB deletions in patients with paraganglioma detected by multiplex PCR: a possible hot spot? Genes, Chromosomes \& Cancer 45 213-219. (doi:10.1002/gcc.20283)
Cascon A, Lopez-Jimenez E, Landa I, Leskela S, Leandro-Garcia LJ, Maliszewska A, Leton R, de la Vega L, Garcia-Barcina MJ, Sanabria C et al. $2009 a$ Rationalization of genetic testing in patients with apparently sporadic pheochromocytoma/paraganglioma. Hormone and Metabolic Research 41 672-675. (doi:10.1055/s-0029-1202814)

Cascon A, Pita G, Burnichon N, Landa I, Lopez-Jimenez E, Montero-Conde C, Leskela S, Leandro-Garcia LJ, Leton R, Rodriguez-Antona C et al. 2009 b Genetics of pheochromocytoma and paraganglioma in Spanish patients. Journal of Clinical Endocrinology and Metabolism 94 1701-1705. (doi:10.1210/jc.2008-2756)

Comino-Mendez I, Gracia-Aznarez FJ, Schiavi F, Landa I, Leandro-Garcia LJ, Leton R, Honrado E, Ramos-Medina R, Caronia D, Pita G et al. 2011 Exome sequencing identifies MAX mutations as a cause of hereditary pheochromocytoma. Nature Genetics 43 663-667. (doi:10.1038/ng.861)

Evans DG, Howard E, Giblin C, Clancy T, Spencer H, Huson SM \& Lalloo F 2010 Birth incidence and prevalence of tumor-prone syndromes: estimates from a UK family genetic register service. American Journal of Medical Genetics. Part A 152A 327-332. (doi:10.1002/ajmg.a.33139)

Hao HX, Khalimonchuk O, Schraders M, Dephoure N, Bayley JP, Kunst H, Devilee P, Cremers CW, Schiffman JD, Bentz BG et al. 2009 SDH5, a gene required for flavination of succinate dehydrogenase, is mutated in paraganglioma. Science 325 1139-1142. (doi:10.1126/science.1175689)

King KS, Prodanov T, Kantorovich V, Fojo T, Hewitt JK, Zacharin M, Wesley R, Lodish M, Raygada M, Gimenez-Roqueplo AP et al. 2011 Metastatic pheochromocytoma/paraganglioma related to primary tumor development in childhood or adolescence: significant link to SDHB mutations. Journal of Clinical Oncology 29 4137-4142. (doi:10.1200/JCO.2011.34.6353)

Mannelli M, Castellano M, Schiavi F, Filetti S, Giacche M, Mori L, Pignataro V, Bernini G, Giache V, Bacca A et al. 2009 Clinically guided genetic screening in a large cohort of Italian patients with pheochromocytomas and/or functional or nonfunctional paragangliomas. Journal of Clinical Endocrinology and Metabolism 94 1541-1547. (doi:10.1210/jc.2008-2419)

Qin Y, Yao L, King EE, Buddavarapu K, Lenci RE, Chocron ES, Lechleiter JD, Sass M, Aronin N, Schiavi F et al. 2010 Germline mutations in TMEM127 confer susceptibility to pheochromocytoma. Nature Genetics 42 229-233. (doi:10.1038/ng.533)

Ricketts CJ 2010 Tumor risks and genotype-phenotype-proteotype analysis in 358 patients with germline mutations in SDHB and SDHD. Human Mutation 31 41-51. (doi:10.1002/humu.21136)

Ricketts CJ, Forman JR, Rattenberry E, Bradshaw N, Lalloo F, Izatt L, Cole TR, Armstrong R, Kumar VK, Morrison PJ et al. 2010 Tumor risks and genotype-phenotype-proteotype analysis in 358 patients with germline mutations in SDHB and SDHD. Human Mutatation 31 41-51.

Schiavi F, Milne RL, Anda E, Blay P, Castellano M, Opocher G, Robledo M \& Cascon A 2010 Are we overestimating the penetrance of mutations in SDHB? Human Mutation 31 761-762. (doi:10.1002/humu.21269)

Welander J, Soderkvist P \& Gimm O 2011 Genetics and clinical characteristics of hereditary pheochromocytomas and paragangliomas. Endocrine-Related Cancer 18 R253-R276. (doi:10.1530/ERC-11-0170)

Wu P, Zhang N, Wang X, Ning X, Li T, Bu D \& Gong K 2012 Family history of von Hippel-Lindau disease was uncommon in Chinese patients: suggesting the higher frequency of de novo mutations in VHL gene in these patients. Journal of Human Genetics 57 238-243. (doi:10.1038/jhg.2012.10)

Yao L, Schiavi F, Cascon A, Qin Y, Inglada-Perez L, King EE, Toledo RA, Ercolino T, Rapizzi E, Ricketts CJ et al. 2010 Spectrum and prevalence of FP/TMEM127 gene mutations in pheochromocytomas and paragangliomas. Journal of the American Medical Association 304 2611-2619. (doi:10.1001/jama.2010.1830)

Received in final form 15 January 2013

Accepted 7 February 2013

Made available online as an Accepted Preprint

12 February 2013 http://erc.endocrinology-journals.org DOI: $10.1530 / E R C-12-0339$ (c) 2013 Society for Endocrinology Printed in Great Britain 